\title{
Screening Newborns for Multiple Organic Acidurias in Dried Filter Paper Urine Samples: Method Development
}

\author{
MENDEL TUCHMAN, MARK T. MCCANN, PAUlA E. JOHNSON, AND BERNARD LEMIEUX \\ Division of Genetics and Metabolism, Departments of Pediatrics and Laboratory Medicine and Pathologl: \\ University of Minnesota, Minneapolis, Minnesola M.T., M.T.M., P.E.J.J 55455 and Quebec Lrine Metabolic \\ Screening Program. Deparment of Pediatrics, University of Sherbrooke Medical Center. Sherbrooke,
} Quebec' Canada JIII 5N4 [B.L.]

\begin{abstract}
Screening urine for inherited and acquired organic acidurias in newborns has the potential of preventing severe disease, mental retardation, and death. A method for screening dried urine filter paper samples for acidic markers of at least $\mathbf{2 0}$ different metabolic conditions has been developed. These conditions include, among others, maple syrup urine disease; methylmalonic, propionic, isovaleric, glutaric, and hydroxymethylglutaric asidurias; methylcrotonylglycinuria; medium-chain acyl-CoA dehydrogenase deficiency; inherited vitamin responsive disorders $\left(B_{12}\right.$, biotin, $\left.B_{2}\right)$, and acquired deficiencies of these vitamins. The preparation of the urine extract is identical to the method we use to screen infants for neuroblastoma. Screening is based on a highly sensitive and specific determination of eight organic acid markers by an automated computerized gas chromatography mass spectrometry system using selected ion monitoring. The markers used for screening are methylmalonic acid, 2-hydroxyisocaproic acid, glutaric acid, propionylglycine, isovalerylglycine, 3methylcrotonylglycine, hexanoylglycine, and 3-phenylpropionylglycine. The extraction efficiencies of these acids from dried filter paper were similar to extraction from water, ranging from about $\mathbf{4 0 \%}$ to $\mathbf{8 0} \%$, except for propionylglycine which showed a low extraction efficiency of $11-13 \%$. The stability of these acids on filter paper exposed to room air and temperature over a period of $15 \mathrm{~d}$ was adequate for the use of this collection method for organic aciduria screening. Normal levels, adjusted to urinary creatinine, were established for these acids in 519 urine filter paper samples obtained from 3-wk-old newborns. This screening method was tested on samples obtained from 12 patients with known organic acidurias including stored urine filter paper collected at 3-wk of age from two infants later found to have organic acidurias. (Pediatr Res 30: 315-321, 1991)
\end{abstract}

Abbreviations

GC-MS, gas chromatography-mass spectrometry TMS, trimethylsilyl

Received January 11, 1991: accepted May 30, 1991

Reprint requests: Mendel Tuchman, M.D., Department of Pediatrics. University of Minnesota, Box 400 Mayo Memorial Building, 402 Delaware Street S.E., Minneapolis, MN 55455 .

Supported in part by the Minnesota Medical Foundation. The Viking Children's Fund, and Public Health Service Grant No. IRO1-CA 46907 from the National Institutes of Health.
Pathologic alterations of normal catabolism of amino acids, fatty acids, carbohydrates, cholesterol, biogenic amines, and steroids frequently result in abnormal excretion patterns of urinary organic acids. These metabolic disorders manifest themselves either by excretion of abnormal organic acids in the urine that are usually not detected in healthy individuals or by excretion of massive amounts of certain acids that are normally present in the urine only in small amounts (1). Most of these organic acidurias are caused by enzyme deficiencies. The deficiency may be due to a structural abnormality in the enzyme protein or it may be caused by deficiency of a specific coenzyme essential for normal catalytic function. Inherited deficiency of a coenzyme may be caused by a defect in absorption, transport, or processing, or it can be acquired secondary to a deficiency in synthetic pathway from the precursor vitamin (2). The degree of abnormal excretion of organic acids in the urine of patients with these metabolic diseases is usually orders of magnitude higher than the small amounts excreted by healthy individuals. Although the amounts of abnormal organic acids excreted by the affected individuals fluctuate according to their metabolic status and dietary intake, in the great majority of affected individuals, abnormal organic aciduria is a persistent finding before therapy.

Neonatal screening for inherited or acquired metabolic diseases is aimed at identifying affected infants early and implementing medical intervention to prevent or minimize the effect of the disease and to provide the opportunity for early genetic counseling. Neonatal screening also provides new knowledge on genetic metabolic defects in the screened population (3). There is little doubt that mental retardation has been prevented in most babies diagnosed by newborn screening programs (e.g phenylketonuria and hypothyroidism) and the cost-benefit ratios of these programs have been reported as highly positive (4). However, organic acidurias, most of which cause severe disease and mental retardation, cannot be screened with the currently available technology using blood samples. The organic acids that mark these disorders are mainly detected in the urine because of the rapid excretion of these water soluble acids by the kidneys; therefore, the concentrations of these markers in the blood are quite low. No screening method that can detect a multitude of organic acidurias has yet been developed.

Metabolic screening of infant urine has been conducted in several programs including programs in Wales (5), Australia (6), Massachusetts (7), and Quebec (8). These programs have provided useful information regarding not only the frequency of many genetic metabolic disorders, but also on the logistics of urine screening. However, screening was done mainly for hyperaminoacidurias caused by either inborn errors of amino acid metabolism or by amino acid renal transport defects. Methylmalonic aciduria has been the only organic aciduria screened and several cases have been detected in Massachusetts (9) and Quebec (10). Other clinically severe or even lethal organic aci- 
durias such as propionic aciduria, isovaleric aciduria, glutaric aciduria, and dicarboxylic acidurias are not covered by these screening methods.

We have developed a urine screening method for the detection of multiple organic acidurias using one test. This test is performed on dried urine absorbed into filter paper. It uses GC-MS technology and employs a sample preparation procedure identical to the one currently used in our laboratory for neuroblastoma screening (11).

\section{MATERIALS AND METHODS}

Materials. Methylmalonic acid, 2-hydroxyisocaproic acid, and glutaric acid, were purchased from Sigma Chemical Co. (St. Louis, MO), and 3,4-dimethoxyphenylacetic (homoveratric) acid was purchased from Aldrich Chemical Co. (Milwaukee, WI). The initial supply of isovalerylglycine, methylcrotonylglycine, hexanoylglycine, and 3-phenylpropionylglycine were generous gifts from Dr. Pierro Rinaldo, Yale University. Subsequently, all the acylglycines were synthesized and crystallized as described before $(12,13)$. Ethyl acetate was purchased from EM Industries (Gibbstown, NJ). N,O bis-(trimethylsilyl) trifluoroacetamide plus $10 \%$ trimethylchlorosilane (Regisil RC-3) was purchased from Regis Chemical Co. (Morton Grove, IL).

Newborn urine filter paper samples. Samples containing dried urine that had been blotted onto filter paper from 3-wk-old babies born in Quebec, Canada, were obtained from the Quebec Urine Metabolic Screening Program for the purpose of establishing normal values of urinary organic acids for this age. Before leaving the hospital, parents were given an explanation pamphlet and a filter paper urine collection kit. Each kit included instructions on how to collect the urine, a $10 \times 10 \mathrm{~cm}$ no. 903 Schleicher and Schuell filter paper (Schleicher and Schuell, Inc., Keene, $\mathrm{NH}$ ), and a return envelope addressed to the screening laboratory at the University Medical Center in Sherbrooke. Parents collected urine by pressing the filter paper onto a wet unsoiled diaper until the paper was thoroughly wet. In addition, the parents were given absorbent paper pads (courtesy of Procter and Gamble Inc.) and instructions to facilitate urine collection if they had difficulties in obtaining urine from the diapers. The soaked filter paper was allowed to dry in room air on a clean, nonabsorbent surface and was then mailed to the laboratory. The mean elapsed time between the collection of the samples and analysis was about 10 $\mathrm{d}$, during which time the samples were kept at room temperature.

Parents of children with known organic acidurias were sent filter paper collection kits and asked to mail their children's urine samples to our laboratory for testing to examine the diagnostic capabilities of the test. In toilet-trained children, the liquid urine $(5 \mathrm{~mL})$ was poured onto the filter paper, which was then dried in room air. In addition, stored filter paper samples collected at 3 wk of age (length of storage at $-20^{\circ} \mathrm{C}, 11$ and $23 \mathrm{mo}$, respectively) from one patient with methylmalonic aciduria and one patient with glutaric aciduria type II were analyzed retroactively.

Organic acid screening assay. Table 1 displays the organic acid markers for the disorders screened by this test. Dried filter paper samples were analyzed as follows. A $20-\mathrm{cm}^{2}$ section was cut from the filter paper, then fan-folded and inserted into a disposable 16 $\times 125$-mm polypropylene tube. Five one hundredths of a micromole $(10 \mu \mathrm{g})$ of 3,4-dimethoxyphenylacetic acid was applied to the filter paper as the internal standard. The tubes were capped with polyethylene caps and the urinary compounds were eluted by mechanical shaking in $5 \mathrm{~mL}$ distilled water for $5 \mathrm{~min}$ with a reciprocating shaker. A $200-\mu \mathrm{L}$ aliquot was removed for urinary creatinine determination by Folin's method using the Jaffe reaction (14). The aqueous eluate was saturated with sodium chloride and acidified with $0.2 \mathrm{~mL} 5 \mathrm{~N} \mathrm{HCl}$. The organic acids were extracted once with $6 \mathrm{~mL}$ of ethyl acetate for 5 min using a mechanical shaker. The organic layer was removed and dried under a stream of nitrogen at $50^{\circ} \mathrm{C}$. Derivatization to form TMS derivatives of the organic acids was accomplished with $100 \mu \mathrm{L}$ of bis(TMS)trifluoroacetamide/trimethylchlorosilane (10:1 vol/ vol) solution for $20 \mathrm{~min}$ at $60^{\circ} \mathrm{C}$, and the derivatized urine extract was then transferred into disposable injection vials.

One $\mu \mathrm{L}$ of the derivatized extract was injected into the gas chromatograph (5890 gas chromatograph; Hewlett Packard, Avondale, PA) by an automatic injection system. The acids were separated on a cross-linked $0.2-\mathrm{mm}$ internal diameter, $25 \mathrm{~m}$ long, $5 \%$ phenylmethylsilicone capillary column with a film thickness of $0.52 \mu \mathrm{m}$ (Ultra 2; Hewlett Packard Co., Avondale, PA). The oven temperature program was started at $100^{\circ} \mathrm{C}$ and increased by $20^{\circ} \mathrm{C} / \mathrm{min}$ up to $270^{\circ} \mathrm{C}$, where it was held for about 5 min, during which time the data were processed and the results reported by computer. Injection port and transfer line temperatures were 250 and $280^{\circ} \mathrm{C}$, respectively. Split injection mode was used with a split ratio of $1: 40$. Flow rate of the helium carrier gas was approximately $1 \mathrm{~mL} / \mathrm{min}$, and its linear velocity was 35 $\mathrm{cm} / \mathrm{s}$. Detection was by mass spectrum detector (5971 quadrupole MSD Hewlett Packard) equipped with 70-eV electron impact ion source utilizing selected ion monitoring mode, monitoring the following ions (in the order of their elution) within their respective time windows: $\mathrm{m} / \mathrm{z} 218$ for methylmalonic aciddiTMS, m/z 261 for 2-hydroxyisocaproic acid-diTMS, m/z 188 for propionylglycine-monoTMS, $\mathrm{m} / \mathrm{z} 261$ for glutaric aciddiTMS, m/z 261 for propionylglycine-diTMS, m/z 216 for isovalerylglycine-monoTMS, $\mathrm{m} / \mathrm{z} 288$ for isovalerylglycine-diTMS, $\mathrm{m} / \mathrm{z} 229$ for 3-methylcrotonylglycine-monoTMS, m/z 286 for 3methylcrotonylglycine-diTMS, m/z 230 for hexanoylglycinemonoTMS, m/z 302 for hexanoylglycine-diTMS, m/z 268 for 3,4-dimethoxyphenylacetic acid-monoTMS (internal standard), $\mathrm{m} / \mathrm{z} 351$ for 3-phenylpropionylglycine-diTMS, and m/z 279 for 3-phenylpropionylglycine-monoTMS. Dwell time for each ion was $10 \mathrm{~ms}$ and the resolution was 0.5 atomic mass units. The criterion for identification of these acids by computer was that the retention time of the peak of interest was less than $\pm 0.5 \%$ from the retention time of the known standard determined before each automated run of multiple samples. Quantitation was performed by internal standard calibration using nonextracted standards with adjustment for variations in detector response for the various acids. Because acylglycine derivatives convert spontaneously from monoTMS to diTMS over several hours, the respective fractions of the mono and diTMS derivatives of the acylglycines were determined by total ion scan analysis before calibrating the selected ions. Results of urinary acid levels are expressed as $\mu \mathrm{mol}$ per $\mathrm{mmol}$ of urinary creatinine and were compared with normal controls (see Results).

Studies on extraction efficiency and stability. Each of these acids [0.05-0.08 $\mu \mathrm{mol}(10 \mu \mathrm{g})]$ was dissolved in methanol, placed on filter paper, allowed to dry, and extracted as described above. The peak areas of the acids were integrated and compared with those obtained from identical amounts of acids extracted from water or subjected to direct derivatization without prior extraction.

The stability of these acids on dried filter paper stored at room temperature was examined by spiking filter papers with $0.05-$ $0.08 \mu \mathrm{mol}(10 \mu \mathrm{g})$ of each of these acids and assaying them after differing lengths of storage time up through $2 \mathrm{wk}$.

\section{RESULTS}

Figure 1 shows a selective ion monitoring chromatogram obtained from a filter paper spiked with $0.05-0.08 \mu \mathrm{mol}(10 \mu \mathrm{g})$ of each of the eight acids and $0.05 \mu \mathrm{mol}(10 \mu \mathrm{g})$ of the internal standard. The acids were separated efficiently by the capillary column. The last eluting peak of interest was phenylpropionylglycine-mono TMS, with a retention time of $8.6 \mathrm{~min}$. When the variability in retention times of the eight acids was examined during a continuous GC-MS run over $12 \mathrm{~h}$, the SD from the mean retention times ranged from \pm 0.00 to $\pm 0.06 \%(n=42)$. An automated GC-MS system equipped with a multitasking computer is capable of running about 100 samples within $24 \mathrm{~h}$ 
Table 1. Disorders, etiology, and markers of organic aciduria screening test

\begin{tabular}{lll}
\hline \multicolumn{1}{c}{ Metabolic disorder } & \multicolumn{1}{c}{ Etiology } & \multicolumn{1}{c}{ Marker } \\
\hline Methylmalonic aciduria & Methylmalonyl-CoA mutase deficiency & Methylmalonic acid \\
Cobalamin A, B, C, D, F mutations & Defects in vitamin B I $_{12}$ processing & Methylmalonic acid \\
Cobalamin deficiency & Dietary or absorptive or transport deficiencies & Methylmalonic acid \\
Maple syrup urine disease & Branched-chain ketoacid dehydrogenase deficiency & 2-hydroxyisocaproic acid \\
Propionic aciduria & Propionyl-CoA carboxylase deficiency & Propionylglycine \\
Glutaric aciduria type I & Glutaryl-CoA dehydrogenase deficiency & Glutaric acid \\
Glutaric aciduria type II & ETF and ETF dehydrogenase deficiency* & Glutaric acid, hexanoylglycine \\
Riboflavin deficiency & Dietary or absorptive or transport deficiencies & Glutaric acid \\
Aminoadipic aciduria & Ketoadipic acid dehydrogenase deficiency & Glutaric acid \\
Isovaleric aciduria & Isovaleryl-CoA dehydrogenase deficiency & Isovalerylglycine \\
Methylcrotonylglycinuria & Methylcrotonyl-CoA carboxylase deficiency & 3-methylcrotonylglycine \\
Biotin deficiency & Dietary or absorptive or transport deficiencies & 3-methylcrotonylglycinc, propionylglycine \\
Multiple carboxylase deficiency & Holocarboxylase synthetase deficiency & 3-methylcrotonylglycine, propionylglycine \\
Biotinidase deficiency & Defects in biotin processing & 3-methylcrotonylglycine, propionylglycine \\
Hydroxymethylglutaric aciduria & Hydroxymethylglutaryl-CoA lyase deficiency & 3-methylcrotonylglycine \\
MCAD deficiency & Medium-chain acyl-CoA dehydrogenase deficiency & Hexanoylglycine, 3-phenylpropionylglycine \\
\hline
\end{tabular}

*ETF, electron transferring flavoprotein.

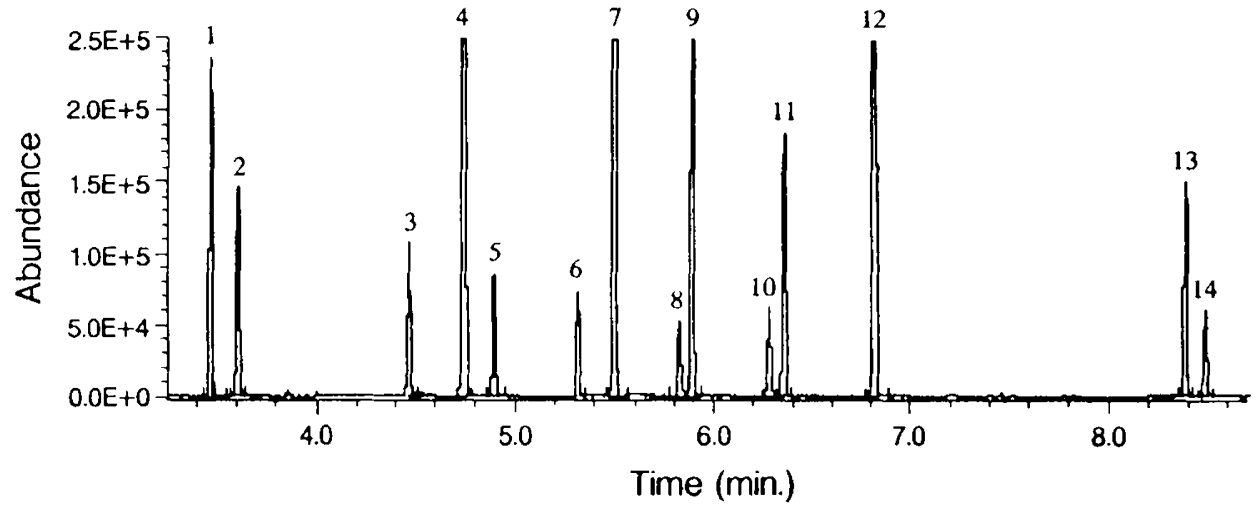

Fig. 1. Selected ion monitoring chromatogram obtained from a standard mixture containing $0.05-0.08 \mu \mathrm{mol}(10 \mu \mathrm{g})$ of each of the markers and the internal standard. Peak identifications and the selected ions monitored for each acid are indicated: 1 , methylmalonic acid-diTMS: 2, 2hydroxyisocaproic acid-diTMS; 3, propionylglycine-monoTMS; 4, glutaric acid-diTMS; 5 , propionylglycine-diTMS; 6 , isovalerylglycine-monoTMS; 7. isovalerylglycine-diTMS; 8,3 -methylcrotonylglycine-monoTMS; 9, 3-methylcrotonylglycine-diTMS: 10 , hexanoylglycine-monoTMS; 11 , hexanoylglycine-diTMS; /2, 3,4-dimethoxyphenylacetic acid (internal standard); 13, 3-phenylpropionylglycine-diTMS: and 14, 3-phenylpropionylglycinemonoTMS.

Table 2. Extraction efficiencies (\%) of organic acids using described method*

\begin{tabular}{ccccccccccc}
\hline & $\mathrm{MM} \dagger$ & $\mathrm{HIC}$ & $\mathrm{PG}$ & GLU & IVG & MCG & HG & DMPA & PPG \\
\hline Filter & 47 & 60 & 13 & 42 & 46 & 38 & 78 & 78 & 78 \\
Water & 45 & 53 & 11 & 42 & 47 & 44 & 73 & 84 & 76 \\
\hline
\end{tabular}

* Mean of the extraction efficiency from three samples compared with the mean of three nonextracted samples of $0.05-0.08 \mu \mathrm{mol}(10 \mu \mathrm{g})$ of each acid.

† MM. methylmalonic acid; HIC, 2-hydroxyisocaproic acid; PG, propionylglycine; GLU, glutaric acid: IVG, isovalerylglycine: MCG, 3methylcrotonylglycine; HG, hexanoylglycine: DMPA, 3,4-dimethoxyphenylacetic acid: and PPG. 3-phenylpropionylglycine.

unattended and without interruption. One laboratory technician can process and prepare for injection $80-100$ samples in a working day.

The extraction efficiencies of the eight acids from dried filter papers are summarized in Table 2. The extraction efficiencies of these acids from dried filter paper were similar to the efficiency of extraction from water, ranging from $38-78 \%$ except for propionylglycine, which had a low extraction efficiency of $11-13 \%$ from both water and filter paper. These extraction efficiencies are adequate for the purpose of screening.

Figure 2 is a graphic illustration of the stability of these organic acids on dried filter paper stored at room temperature for a duration of $2 \mathrm{wk}$. All eight acids were stable during the period of testing. Some of the variability could be accounted for by variation in the sensitivity of the mass-spectrum detector and extraction efficiency.

Table 3 and Figure 3 summarize the quantitative results ob- tained from 3-wk-old newborns from the Province of Quebec in Canada. Glutaric acid and methylmalonic acid were the most common organic acids detected in this population, whereas 2 hydroxyisocaproic acid and phenylpropionylglycine were virtually undetectable in the urine of normal newborns by this method. The other five acids were detected in the minority of the samples. We have arbitrarily chosen 5 SD above the mean as the cutoff for a positive screen. The distribution of normal levels of these acids relative to the urinary creatinine concentration is shown in Figure 3.

The method described herein was evaluated by analyzing filter paper samples obtained from children with known organic acidurias. Table 4 summarizes the results obtained. Ten out of the 12 patients had at least one of the acid markers elevated more than 5 SD above the mean. In a patient with cobalamin $\mathrm{C}$ mutation and a patient with hydroxymethylglutaric aciduria, the respective marker (methylmalonic acid and methylcrotonylgly- 

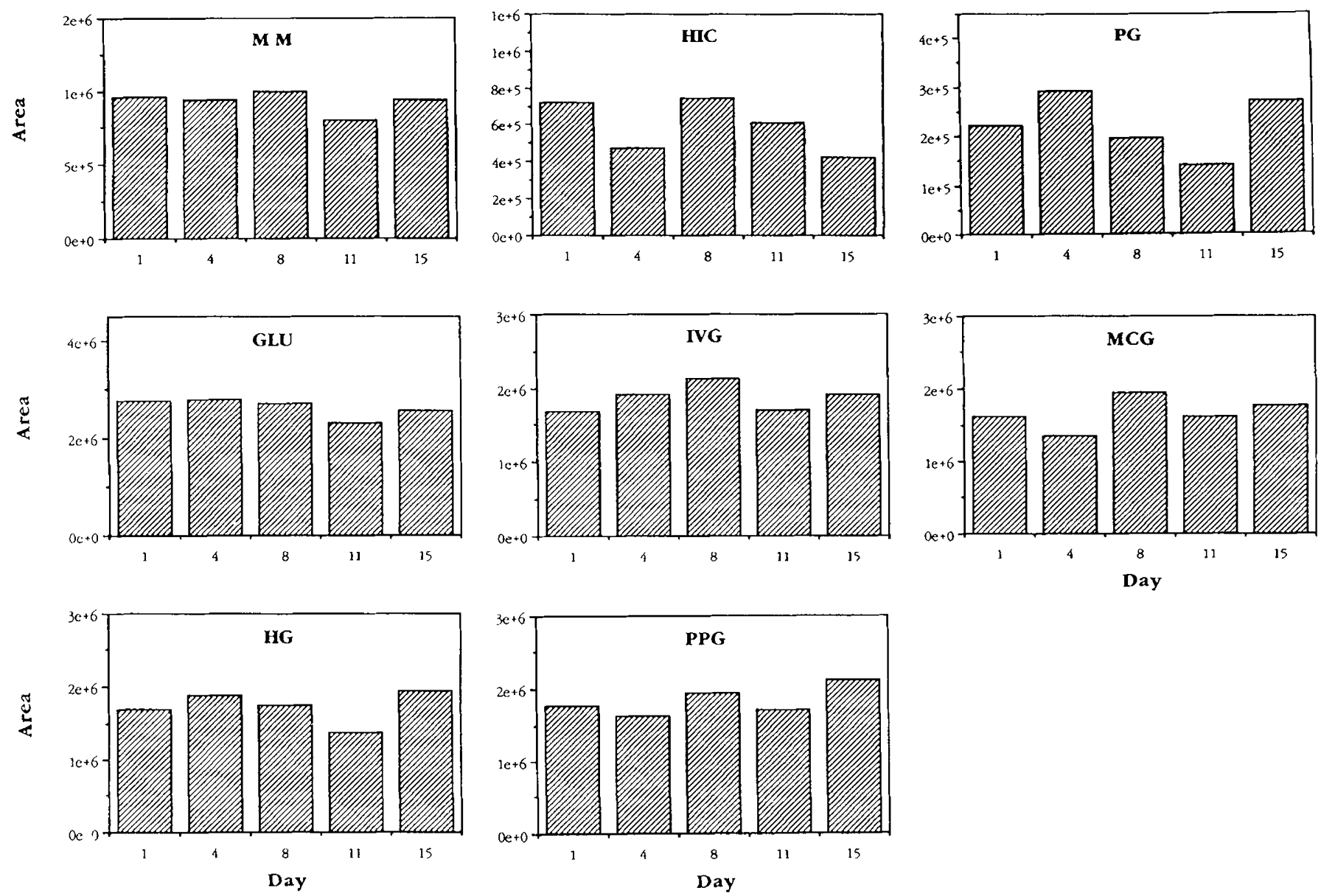

Fig. 2. Stability of the organic acids on dried filter paper stored at room temperature up to $15 \mathrm{~d}$. Day 1 is the day the filter papers were spiked with the acids. MM, methylmalonic acid; HIC, hydroxyisocaproic acid; PG, propionylglycine; GLU, glutaric acid; IVG, isovalerylglycine; MCG, methylcrotonylglycine; HG, hexanoylglycine; DMPA, dimethoxyphenylacetic acid; PPG, phenylpropionylglycine.

Table 3. Results of organic acid screening obtained from filter paper samples of 519 3-wk-old newborns*

\begin{tabular}{|c|c|c|c|c|c|c|c|c|}
\hline & $M M+$ & $\mathrm{HIC}$ & PG & GLU & IVG & MCG & $\mathrm{HG}$ & PPG \\
\hline Mean $+5 \mathrm{SD}$ & $\begin{array}{c}90 \\
(94)\end{array}$ & NAt & $\begin{array}{c}5 \\
(6)\end{array}$ & 15 & 3 & $\begin{array}{c}74 \\
0\end{array}$ & 13 & $\begin{array}{c}7 \\
(4)\end{array}$ \\
\hline Maximum $§$ & $\begin{array}{c}229 \\
(239)\end{array}$ & $\begin{array}{c}14 \\
(16)\end{array}$ & $\begin{array}{c}5 \\
5 \\
(6)\end{array}$ & $\begin{array}{c}22 \\
(26)\end{array}$ & $\begin{array}{c}3 \\
(4)\end{array}$ & $\begin{array}{c}146 \\
(203)\end{array}$ & $\begin{array}{c}19 \\
(29)\end{array}$ & $\begin{array}{c}3 \\
3 \\
(5)\end{array}$ \\
\hline Number detected (out of 519) & 418 & 2 & 35 & 495 & 130 & 103 & 66 & 4 \\
\hline
\end{tabular}

* In $\mu \mathrm{mol}$ per mmol urinary creatinine. Values in parentheses in $\mu \mathrm{g}$ per mg urinary creatinine.

† MM, methylmalonic acid; HIC, 2-hydroxyisocaproic acid; PG, propionylglycine; GLU, glutaric acid; IVG, isovalerylglycine; MGG, 3methylcrotonylglycine; HG, hexanoylglycine; PPG, 3-phenylpropionylglycine.

$\ddagger N A$, not applicable.

$\$$ Highest level detected.

cine) levels were less than $5 \mathrm{SD}$ above the mean, probably as a result of the patients being on therapy. In the case of methylcrotonylglycine, the normal levels $(<5 \mathrm{SD}$ above the mean) were skewed upward because of one very elevated level included in the normals. One patient with methylmalonic aciduria and one patient with glutaric aciduria type II had their 3-wk screening filter papers retrieved from storage at $-25^{\circ} \mathrm{C}$ and analyzed 11 and 23 mo after collection, respectively. Note that in the sample of the patient with glutaric aciduria the presence of high levels of hexanoylglycine and isovalerylglycine in addition to glutaric acid indicates the diagnosis of glutaric aciduria type II. Some of these disorders were also associated with elevations of organic acids that are specific markers for other disorders. For example, in one patient with propionic aciduria on therapy, propionylglycine levels were not very elevated, but the levels of methylcrotonylglycine were very high. Thus, this screening test contains more than a single marker for several of the organic acidurias screened, and a single marker will frequently detect more than one metabolic condition.

\section{DISCUSSION}

All of the conditions screened by the test, except possibly aminoadipic aciduria, have been associated with mental retardation, which in many cases had been severe. Moreover, all of these organic acidurias are associated with severe acute or chronic disease, and occasionally death occurs during acute metabolic decompensation. Sudden infant death in apparently healthy infants with medium-chain acyl-CoA dehydrogenase deficiency has also been described $(15,16)$. Blindness and deafness have been reported in some patients with these conditions, as well as increased susceptibility to infections.

A few of the organic acidurias proposed for screening here may not be inherited. For example, various vitamin deficiencies 

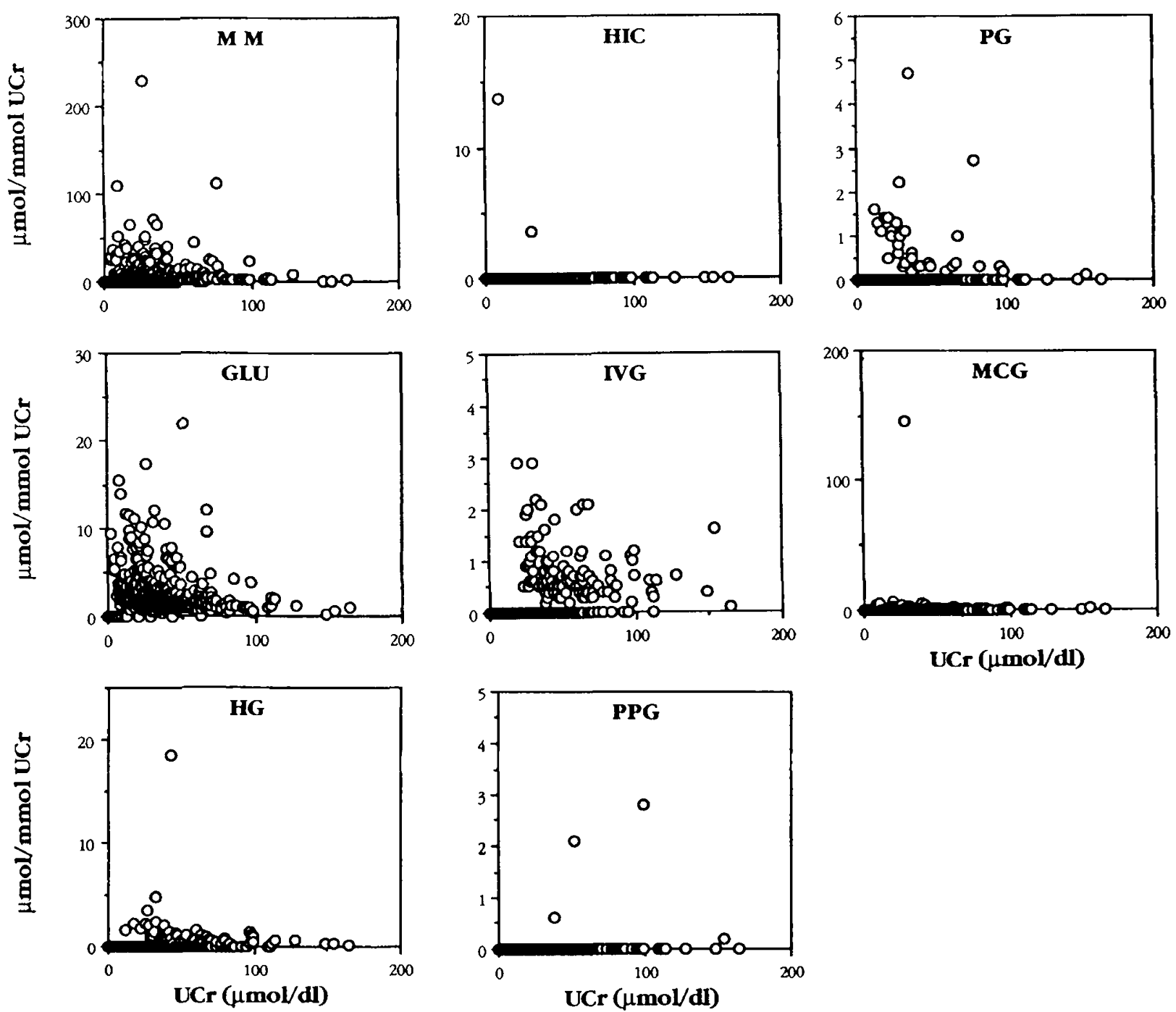

Fig. 3. Quantitative results of the eight urinary acid markers in filter paper samples obtained from 519 3-wk old newborns using the screening test described above. Results are expressed in $\mu \mathrm{mol} / \mathrm{mmol}$ urinary creatinine and are stratified according to the creatinine concentration $(\mu \mathrm{mol} / \mathrm{dL})$ in the filter paper elution liquid. Abbreviations for the acid names are the same as those in Figure 2.

such as cobalamin (17-19) or potentially biotin and riboflavin deficiency could be acquired because of a maternal deficiency state. Acquired deficiency or inherited dependency on these vitamins in infants has been reported to cause various clinical problems or has the potential to cause metabolic aberrations that may cause mental retardation, severe disease, and even death $(17,20-27)$. Therapy for all conditions is available and has been effective to a variable degree. In vitamin deficiency states or in vitamin-dependent inherited defects, administration of the specific vitamin or its derivative resulted in marked improvement or complete recovery $(17-21,23-27)$. Other nonvitamin-dependent organic acidurias have been treated with dietary manipulations, administration of natural nutritional factors, and medications $(28,29)$. These measures can result in prevention of mental retardation and acute metabolic decompensation.

The method proposed here for screening of organic acidurias has the advantage of being both specific and sensitive because of the GC-MS methodology used. Filter paper urine samples are adequate for screening as in the case of screening for amino aciduria and neuroblastoma. Previous work has shown that filter paper urine samples are adequate for urinary organic acid determination (30). The use of a capillary gas-chromatography column provides high-efficiency separation of the acids, and monitoring specific ions within a narrow time window during the run maximizes the specificity of the detection of each acid. Maximal sensitivity and specificity of this method is also due to the fact that patients with organic acidurias usually excrete very high levels of organic acids in their urine compared with normal individuals. Possible exceptions to the above observation are newborns with medium-chain acyl-CoA dehydrogenase deficiency who may have yet to establish bacterial flora capable of generating phenylpropionic acid and, therefore, may not excrete increased amounts of phenylpropionylglycine $(31,32)$. Hexanoylglycine was therefore included as an additional marker for detection of medium-chain acyl-CoA dehydrogenase deficiency, which we hope will help in the early detection of these patients. The intermittent type of maple syrup urine disease may also not be detectable by this method due to the intermittent nature of the biochemical abnormalities (33). Additional advantages of this method are that each organic acid marker screens more than one metabolic disorder and that several disorders frequently cause enhanced excretion of more than one urinary acid included in the screen, thus improving the reliability of the method. It is possible that after obtaining additional data regarding hexanoylglycine and phenylpropionylglycine in newborns with mediumchain acyl-CoA dehydrogenase deficiency we will be able to drop phenylpropionylglycine as a screening marker, thus shortening the run time of each sample by about $1.5 \mathrm{~min}$. A multitasking computer that is now available for the GC-MS system will further shorten the analysis time. Moreover, this method is flexible, 
Table 4. Screening urine for organic acidurias in patients with known disorders*

\begin{tabular}{|c|c|c|c|c|c|c|c|c|c|}
\hline Diagnosist & $\begin{array}{l}\text { Age } \\
(\mathrm{y})\end{array}$ & MM‡ & HIC & PG & GLU & IVG & MCG & $\mathrm{HG}$ & PPG \\
\hline Methylmalonic & 0.1 & $\begin{array}{c}982 \\
(1023)\end{array}$ & $\begin{array}{c}0 \\
(0)\end{array}$ & $\begin{array}{c}0 \\
(0)\end{array}$ & $\begin{array}{c}6 \\
\text { (7) }\end{array}$ & $\begin{array}{c}0 \\
(0)\end{array}$ & $\begin{array}{c}0 \\
(0)\end{array}$ & $\begin{array}{c}0 \\
(0)\end{array}$ & $\begin{array}{c}0 \\
(0)\end{array}$ \\
\hline $\mathrm{cbl} \mathrm{A}$ & 1.3 & $\begin{array}{c}177 \\
(185)\end{array}$ & $\begin{array}{c}0 \\
(0)\end{array}$ & $\begin{array}{c}0 \\
(0)\end{array}$ & $\begin{array}{c}0 \\
(0)\end{array}$ & $\begin{array}{c}0 \\
(0)\end{array}$ & $\begin{array}{c}0 \\
(0)\end{array}$ & $\begin{array}{c}0 \\
(0)\end{array}$ & $\begin{array}{c}0 \\
(0)\end{array}$ \\
\hline $\mathrm{cbl} \mathrm{C}$ & 2.4 & $\begin{array}{c}50 \\
(52)\end{array}$ & $\begin{array}{c}0 \\
(0)\end{array}$ & $\begin{array}{c}0 \\
(0)\end{array}$ & $\begin{array}{c}1 \\
(1)\end{array}$ & $\begin{array}{c}0 \\
(0)\end{array}$ & $\begin{array}{c}1 \\
(2)\end{array}$ & $\begin{array}{c}0 \\
(0)\end{array}$ & $\begin{array}{c}0 \\
(0)\end{array}$ \\
\hline Propionic & 2.3 & $\begin{array}{c}0 \\
(0)\end{array}$ & $\begin{array}{c}0 \\
(0)\end{array}$ & $\begin{array}{c}13 \\
(15)\end{array}$ & $\begin{array}{c}3 \\
\text { (3) }\end{array}$ & $\begin{array}{c}3 \\
(4)\end{array}$ & $\begin{array}{c}9 \\
(12)\end{array}$ & $\begin{array}{c}7 \\
\text { (11) }\end{array}$ & $\begin{array}{c}0 \\
(0)\end{array}$ \\
\hline Propionic & 8.3 & $\begin{array}{c}0 \\
(0)\end{array}$ & $\begin{array}{c}0 \\
(0)\end{array}$ & $\begin{array}{c}4 \\
(5)\end{array}$ & $\begin{array}{c}3 \\
(3)\end{array}$ & $\begin{array}{c}8 \\
(12)\end{array}$ & $\begin{array}{c}150 \\
(208)\end{array}$ & $\begin{array}{c}10 \\
(15)\end{array}$ & $\begin{array}{c}0 \\
(0)\end{array}$ \\
\hline Propionic & 3.0 & $\begin{array}{c}0 \\
(0)\end{array}$ & $\begin{array}{c}0 \\
(0)\end{array}$ & $\begin{array}{l}14 \\
(16)\end{array}$ & $\begin{array}{c}2 \\
(2)\end{array}$ & $\begin{array}{c}2 \\
(3)\end{array}$ & $\begin{array}{c}5 \\
(7)\end{array}$ & $\begin{array}{c}3 \\
(5)\end{array}$ & (1) \\
\hline Glutaric II & 0.1 & $\begin{array}{c}6 \\
(6)\end{array}$ & $\begin{array}{c}0 \\
(0)\end{array}$ & $\begin{array}{c}0 \\
(0)\end{array}$ & $\begin{array}{c}762 \\
(886)\end{array}$ & $\begin{array}{c}18 \\
(26)\end{array}$ & $\begin{array}{c}6 \\
(8)\end{array}$ & $\begin{array}{c}189 \\
(291)\end{array}$ & $\begin{array}{c}2 \\
\text { (3) }\end{array}$ \\
\hline Aminoadipic & 3.0 & $\begin{array}{c}2 \\
(2)\end{array}$ & $\begin{array}{c}0 \\
(0)\end{array}$ & $\begin{array}{c}1 \\
\text { (1) }\end{array}$ & $\begin{array}{c}58 \\
(67)\end{array}$ & $\begin{array}{c}2 \\
(3)\end{array}$ & $\begin{array}{c}1 \\
(2)\end{array}$ & $\begin{array}{c}0 \\
(0)\end{array}$ & $\begin{array}{c}0 \\
(0)\end{array}$ \\
\hline $\mathrm{HMG}$ & 2.6 & $\begin{array}{c}0 \\
(0)\end{array}$ & $\begin{array}{c}0 \\
(0)\end{array}$ & $\begin{array}{c}0 \\
(0)\end{array}$ & $\begin{array}{c}4 \\
(5)\end{array}$ & $\begin{array}{c}1 \\
(1)\end{array}$ & $\begin{array}{c}16 \\
(23)\end{array}$ & $\begin{array}{c}0 \\
(0)\end{array}$ & $\begin{array}{c}0 \\
(0)\end{array}$ \\
\hline MCG & 4.5 & $\begin{array}{c}0 \\
(0)\end{array}$ & $\begin{array}{c}0 \\
(0)\end{array}$ & $\begin{array}{c}0 \\
(0)\end{array}$ & $\begin{array}{l}1 \\
\text { (I) }\end{array}$ & $\begin{array}{c}2 \\
(3)\end{array}$ & $\begin{array}{c}578 \\
(803)\end{array}$ & (I) & $\begin{array}{c}0 \\
(0)\end{array}$ \\
\hline MCG & 5.7 & $\begin{array}{c}0 \\
(0)\end{array}$ & $\begin{array}{c}0 \\
(0)\end{array}$ & $\begin{array}{c}0 \\
(0)\end{array}$ & $\begin{array}{l}1 \\
\text { (1) }\end{array}$ & $\begin{array}{c}5 \\
(7)\end{array}$ & $\begin{array}{c}1080 \\
(1500)\end{array}$ & $\begin{array}{c}3 \\
\text { (5) }\end{array}$ & $\begin{array}{c}0 \\
(0)\end{array}$ \\
\hline MCAD & 2.5 & $\begin{array}{c}1 \\
(1)\end{array}$ & $\begin{array}{c}0 \\
(0)\end{array}$ & $\begin{array}{c}0 \\
(0)\end{array}$ & $\begin{array}{c}0 \\
(0)\end{array}$ & $\begin{array}{c}2 \\
(3)\end{array}$ & $\begin{array}{c}1 \\
(1)\end{array}$ & $\begin{array}{c}63 \\
(97)\end{array}$ & $\begin{array}{c}170 \\
(309)\end{array}$ \\
\hline
\end{tabular}

* In $\mu \mathrm{mol}$ per mmol urinary creatinine. Values in parentheses in $\mu \mathrm{g} / \mathrm{mg}$ urinary creatinine. Values in bold are greater than $5 \mathrm{SD}$ above the mean.

$\dagger \mathrm{cbl}$ A, cobalamin A mutation; cbl C. cobalamin C mutation; HMG, hydroxymethylglutaric aciduria; MCG, methylcrotonylglycinuria; MCAD, medium-chain acyl-CoA dehydrogenase deficiency.

$\ddagger$ MM. methylmalonic acid; HIC, 2-hydroxyisocaproic acid; PG, propionylglycine; GLU, glutaric acid; IVG, isovalerylglycine; MCG, 3methylcrotonylglycine; HG, hexanoylglycine; $\mathrm{PPG}$, 3-phenylpropionylglycine.

allowing other organic acid markers to be added or to replace existing ones if applicable to certain populations.

Mass screening for multiple organic acidurias in urine of newborns has not been previously attempted because assays for such screening may have been perceived as complex, time consuming, and expensive. We present a method here that could be used for such screening. A similar method is already used as a confirmatory test in the Quebec neuroblastoma screening project (11) and for neuroblastoma screening in northern England (34). The resources needed for mass screening of multiple organic acidurias are more expensive than those required for blood mass screening of phenylketonuria and neonatal hypothyroidism. Based on experience from our neuroblastomas screening project, we estimate the cost of one GC-MS assay for mass screening at about $\$ 4.50$. This cost includes salaries of personnel, depreciation of equipment, and supplies. It does not include the expense of establishing an infrastructure for statewide urine collection from babies. The real combined incidence of the organic acidurias detectable by this screening method is unknown. A conservative estimate of $I$ in 3000 would put the cost of one detected case at $\$ 13,500$, which may be offset by the high cost of mental retardation, severe disease, or death. It is possible that screening for organic acidurias will uncover a higher incidence of acquired vitamin deficiencies that are treatable. Those reversible disorders can then be easily and effectively managed with minimal cost by supplementing the specific vitamins. An economical advantage of this screening method is that one urine extract from a filter paper prepared for GC-MS analysis is suitable for both organic aciduria screening and neuroblastoma screening using the same equipment and preparative procedures. Thus, these two screening programs can be performed using the same urine samples, facilities, equipment, and personnel.

Acknowledgments. The authors thank Dr. Pierro Rinaldo for the generous gift of synthetic organic acids; Drs. William Woods, Charles Scriver, and Harvey Levy for their thoughtful sugges- tions; and Mark M. Thompson and Abigail Tilsner for their help in preparing this manuscript.

\section{REFERENCES}

1. Goodman SI, Markey SP 1981 Diagnosis of Organic Acidemias by Gas Chromatography Mass Spectrometry. In: Laboratory and Research Methods in Biology and Medicine, Vol 6, Alan R Liss, New York, pp 45-114

2. Rosenberg LE 1970 Vitamin-dependent genetic disease. Hosp Pract (Off) July:59-66

3. Scriver CR 1985 Population screening: report of a workshop: prevention of physical and mental congenital defects, part B: epidemiology, early detection and therapy, and environmental factors. Prog Clin Biol Res 163B:89-152

4. Tiwary CM 1987 Proposed guidelines for screening of metabolic and endocrine diseases of dependent neonates of the U.S. armed forces. Clin Pediatr 26:349354

5. Bradley DM 1975 Screening for inherited metabolic disease in Wales using urine-impregnated filter paper. Arch Dis Child 50:264-268

6. Wilcken B, Snith A, Brown DA 1980 Urine screening for aminoacidopathies: is it beneficial? Results of a long-term follow-up of cases detected by screening one million babies. J Pediatr 97:492-497

7. Levy HL, Madigan PM, Shih VE 1972 Massachusetts metabolic disorders screening program. I. Technics and results of urine screening. Pediatrics 49:825-836

8. Lemieux B, Auray-Blais, Giguere R, Shapcott D, Scriver CD 1988 Newborn urine screening experience with over one million infants in the Quebec network of genetic medicine. J Inherited Metab Dis 11:45-55

9. Coulombe JT, Shih VE, Levy HL 1981 Massachusetts metabolic disorders screening program. II. Methylmalonic aciduria. Pediatrics 67:26-31

10. Auray-Blais C. Giguère R. Ogier H, Laframboise R. Clow C, Lemieux B 1989 Methylmalonic aciduria: high incidence of cases taken from 1 million analyses detected in the province of Quebec. In: Schmidt BJ (ed) Current Trends in Infant Screening. Elsevier Science Publishers B.V., Amsterdam, The Netherlands, pp 197-203

11. Tuchman M, Lemieux B, Auray-Blais C, Robison LL. Giguere R, McCann MT, Woods WG 1990 Screening for neuroblastoma at 3 weeks of age: methods and preliminary results from the Quebec neuroblastoma screening project. Pediatrics $86: 765-773$

12. O'Neill Rowley B, Gerritsen T 1975 Identification of N-acylglycines by gasliquid chromatography. Clin Chim Acta 62:13-19

13. Gregersen N, Keiding K, Kolvraa S 1979 N-acylglycines: gas chromatographic mass spectrometric identification and determination in urine by selected ion monitoring. Biomed Mass Spectrom 6:339-443

14. Folin O, Wu H 1947 Method cited In: Hawk PB, Oser BL, Summerson WH (eds) Practical Physiology Chemistry. Blakiston, Philadelphia, pp 839-842 
15. Roe CR, Millington DS, Maltby DA, Kinnebrew P 1986 Recognition of medium-chain acyl-CoA dehydrogenase deficiency in asymptomatic siblings of children dying of sudden infant death or Reye-like syndromes. J Pediatr 108:13-18

16. Duran M, Hofkamp M, Rhead WJ, Saudubray JM. Wadman SK 1986 Sudden child death and "healthy" affected family members with medium-chain acylcoenzyme A dehydrogenase deficiency. Pediatrics 78:1052-1057

17. Higginbottom MC, Sweetman L. Nyhan WL 1978 A syndrome of methylmalonic aciduria, homocystinuria, megaloblastic anemia and neurologic abnormalities in a vitamin $B_{12}$-deficient breast-fed infant of a strict vegetarian. $N$ Engl J Med 299:317-323

18. Sadowitz PD, Livingston A, Cavanaugh RM 1986 Developmental regression as an early manifestation of vitamin $B_{12}$ deficiency. Clin Pediatr 25:369-371

19. Michaud JL, Lemieux B, Ogier H, Lambert MA 1991 Nutritional vitamin $B_{12}$ deficiency: two cases detected by the Quebec newborn screening program. Eur J Pediatr (in press)

20. Shih VE, Axel SM, Tewksbury JC, Watkins D, Cooper BA, Rosenblatt DS 1989 Defective lysosomal release of vitamin $B_{12}$ (cblF): a hereditary cobalamin metabolic disorder associated with sudden death. Am J Med Genet 33:555-563

21. Gregersen N, Wintzensen H, Christensen SKE, Christensen MF, Brandt NJ Rasmussen K $1982 \mathrm{C}_{6}-\mathrm{C}_{10}$-Dicarboxylic aciduria: investigations of a patient with riboflavin responsive multiple acyl-CoA dehydrogenation defects. Pediatr Res 16:861-868

22. Burton BK, Roach ES, Wolf B, Weissbecker KA 1987 Sudden death associated with biotinidase deficiency. [letter] Pediatrics 79:482-483

23. Swick HM, Kien CL 1983 Biotin deficiency with neurologic and cutaneous manifestations but without organic aciduria. J Pediatr 103:265-267

24. Sweetman L, Surh L, Baker H, Peterson RM. Nyhan WL 1981 Clinical and metabolic abnormalities in a boy with dietary deficiency of biotin. Pediatrics $68: 553-558$

25. Wolf B, Grier RE, Allen RJ, Goodman SI, Kien CL, Parker WD. Howell DM, Hurst DL 1983 Phenotypic variation in biotinidase deficiency. J Pediatr 103:233-237

26. Rosenblatt DS, Thomas IT, Watkins D, Cooper BA, Erbe RW 1987 Vitamin $B_{12}$ responsive homocystinuria and megaloblastic anemia: heterogeneity in methylcobalamin deficiency. Am J Med Genet 26:377-383

27. Schuh S, Rosenbiatt DS, Cooper BA, Schroeder ML, Bishop AJ, Seargeant LE, Haworth JC 1984 Homocystinuria and megaloblastic anemia responsive to vitamin $B_{12}$ therapy. $N$ Engl J Med 310:686-690

28. Valle D 1987 Genetic disease: an overview of current therapy. Hosp Pract 22:167-182

29. Arn PH, Valle DL, Brusilow SW 1988 Inborn errors of metabolism: not rare not hopeless. Contemp Pediatr December:47-63

30. Chamberlin BA, Sweeley CC 1987 Metabolic profiles of urinary acids recovered from absorbent filter paper. Clin Chem 33:572-576

31. Rinaldo P, O'Shea JJ, Welch RD. Tanaka K 1990 The enzymatic basis for the dehydrogenation of 3-phenylpropionic acid: in vitro reaction of 3-phenylpropionyl-CoA with various acyl-CoA dehydrogenases. Pediatr Res 27:501-507

32. Bennett MJ Coates PM Hale DE, Millington DS, Pollitt RJ, Rinaldo P, Roe CR. Tanaka K 1990 Analysis of abnormal urinary metabolites in the newborn period in medium-chain acyl-CoA dehydrogenase deficiency. $J$ Inherited Metab Dis 13:707-715

33. Irwin WC, Martel SB, Goluboff N 1971 Intermittent-branched chain ketonuria (variant of maple syrup urine disease). Clin Biochem 4:52-58

34. McGill AC, Seviour JA. Dale G, Craft AW 1988 Screening for neuroblastoma by gas chromatography/mass spectrometry in the northern region. Ann Clin Biochem 25(suppl): $132 \mathrm{~s}-133 \mathrm{~s}$ 